\title{
The role of knowledge management in enhancing government service-delivery in Kenyal
}

\author{
Ezra Ondari-Okemwa², \\ University of Fort Hare, Alice, South Africa \\ eookemwa@yahoo.com \\ Janet Gretchen Smith ${ }^{3}$ \\ University of Cape Town, Cape Town \\ gretchen.smith@uct.ac.za
}

\begin{abstract}
This article explores the role that knowledge management $(K M)$ can play to support governance, performance effectiveness, and service delivery in government agencies in Kenya. It further addresses the challenges and problems which act as impediments to introducing KM and engendering a knowledge society. A major factor impeding the effective introduction of knowledge management practices is that the Kenyan civil service is particularly embedded in bureaucracy and very few incentives are provided to encourage civil servants to generate, distribute and share knowledge and information. Many employees in the Kenyan civil service are traditional career civil servants, who cannot envisage and appreciate the potential of knowledge management and the benefits of knowledge leveraging. They are also wary of sharing knowledge, as they think that by hoarding knowledge they enhance their value and competitiveness. The paper is based on data derived from the literature that was integrated with results obtained from a study conducted by OndariOkemwa (2006) for a PhD research project.
\end{abstract}

Keywords: Kenya; government agencies; public sector; public service delivery; knowledge management

\section{Introduction}

The World Bank (200I) avers that knowledge management has become a fundamental source of wealth creation, supplementing industrial capital and land. The World Bank sees knowledge management as representing a management modernisation challenge for the public sector which involves adapting classical management tools in a way that systematically promotes knowledge sharing. The sharing of knowledge in organisations or departments is one of the fundamental functions of any knowledge management programme. It is the contention of the World Bank that countries are anxious to place knowledge management programmes in the public sector but lack the experience or knowledge to do so. This is true not only for Kenya, but for nearly all the countries in the sub-Saharan Africa region. Countries elsewhere in the world may have initiated and implemented knowledge management programmes in the civil service, but most countries in the sub-Saharan region are yet to initiate knowledge management programmes in their civil services.

The civil service in sub-Saharan Africa is still bureaucratic and rigid in its operations. Knowledge management is not as yet embraced in the civil services across the sub-Saharan region. Withers (2006) suggests that for the public service, a key requirement is that of taking knowledge management seriously - at least as seriously as chief finance officers for finances and chief information officers for information technology - as a key part of agency management. Withers explains that such management should embrace systematic oversight of the stock, use, generation and retention of knowledge and information, with particular attention to the placement of this in executive decision-making and the incentive and reward structures of a department or agency.

Kenya, like most countries in the sub-Saharan region and in contrast to many countries in the developed world, has not as yet productively integrated knowledge management into its government agencies (Ondari-Okemwa, 2006). This tardiness can be attributed to the fact that knowledge is not leveraged effectively and because Kenya lags far behind developed countries as far as the application of information and communication technologies and the introduction of egovernance is concerned.

The low scores Kenya achieves on the variables which determine a country's capacity to effect a knowledge economy suggests that much work must be done to engender a society where knowledge is freely generated and effectively used in the public sector. The civil service is further plagued with numerous impediments that inhibit the generation and sharing

I. This paper is a re-worked version of a paper originally presented at the $4^{\text {th }}$ ICICKM Conference held on I5-16 October, 2007 at the University of Stellenbosch Business School, South Africa.

2. Ezra Ondari-Okemwa $(\mathrm{PhD})$, is a senior lecturer and Head, Department of Library and Information Science, University of Fort Hare, Alice, South Africa.

3. Janet Gretchen Smith (PhD), is senior lecturer, Department of Information and Library Studies, University of Cape Town, South Africa. 
of knowledge, the most severe of which are its entrenched bureaucracy, lack of incentives, cultural barriers and technology inadequacies (Ondari-Okemwa, 2006). With reference to technological barriers, it is evident that the ICT infrastructure urgently needs upgrading to facilitate the introduction of e-governance, which in turn will enable the effective implementation of knowledge management programmes. Despite these impediments, it is our conviction that the delivery of basic government services can only be improved if the civil service were to adopt knowledge management practices that are firmly integrated into service delivery procedures. Civil servants should further be encouraged and motivated to actively generate, manage and share knowledge and information. We therefore suggest that the Kenyan public service introduces knowledge management practices and integrates them effectively to ameliorate the situation and significantly improve government service-delivery.

\section{Problem statement}

These authors have no doubt that a multitude of knowledge flows through Kenyan civil every day. However, nobody seems to account for the knowledge that the Kenyan civil servants require for present and future needs, how to acquire that knowledge, the kind of knowledge that individual employees in the civil service possess and how to share such knowledge with others. Nobody seems to know who in the Kenyan civil service needs what knowledge, when, and how such knowledge should be delivered. Further, it does not appear to these authors that those in top-level management in the Kenyan civil service are aware that knowledge can be generated within the various departments of government. They also do not seem to realise that some knowledge that may be required is already owned by employees of the various government departments.

Given that knowledge is now considered an important factor of production and wealth creation in the knowledge society, we contend that there is an urgent need to consider how knowledge should be managed effectively in the Kenyan civil service and the civil services of other sub-Saharan African countries to enable quality government service delivery. Knowledge management can also enable governments in the sub-Saharan region to achieve a competitive advantage in the now increasingly global economy. In a knowledge society, the basic economic resource is no longer capital, or natural resources or even labour, but knowledge. Knowledge is now recognised as a resource that is on a par with other economic resources. As a resource, it should be managed and planned for systematically, just like any other economic resource. Many factors contribute to poor delivery of government services in Kenya and other countries in the subSaharan African region. Lack of knowledge management and therefore a low level of knowledge and information sharing in the civil service has been identified as one of the prime contributors to poor government service delivery. In recent years, it has been invariably suggested that knowledge management can drastically improve service delivery in any civil service.

\section{I Objectives of the study}

It is not yet clear to the civil service in Kenya and the rest of the sub-Saharan Africa, that knowledge management may contribute to good governance, effective performance and consequently superior service delivery. Against this backdrop, this study was conducted with the following broad objectives:

- To show how knowledge management may improve the delivery of government services in Kenya and in the rest of sub-Saharan Africa;

- Establish why civil servants in the Kenya and other sub-Saharan civil services do not freely share knowledge and information;

- Explore ways of integrating knowledge management in the Kenyan civil service and other civil services in the subSaharan African region; and

- Give suggestions on how civil servants in Kenya and other sub-Saharan African countries may be motivated to generate, manage and share knowledge and information.

\subsection{Knowledge management}

Knowledge management has been defined in various ways; Sun (2004), for example, states that it is basically concerned with knowledge processing that is permeated by each of the following stages:

Understanding and discovering knowledge; capturing and acquiring knowledge from a variety of sources; selecting, filtering and classifying existing knowledge; storing and saving knowledge; designing knowledge ontologies; adapting and/ or creating new knowledge; measuring and evaluating knowledge; visualising knowledge; distributing and/or transferring knowledge to others; sharing and applying knowledge; retaining and maintaining knowledge as an asset.

Alavi and Leidner (1999), in turn, define knowledge management as a systematic and organisationally specific process for acquiring, organising and communicating both tacit and explicit knowledge so that employees may utilise it to be more

SA JnI Libs \& Info Sci 2009, 75(I) 
effective and productive in their work. Knowledge management seeks to promote re-use, sharing and re-purposing of an organisation's tacit and explicit knowledge and a shared awareness of the state of an organisation's environment.

The differentiation between tacit and explicit knowledge was first mooted by Nonaka and several of his associates (Nonaka 1994, Nonaka and Konno 1998, Nonaka and Takeuchi 1995). It is their view that explicit knowledge can be expressed in words or numbers, it can be shared in the form of data, scientific formulae, specifications, manuals etc., and it can be readily transmitted between individuals, formally and systematically. Tacit knowledge, on the other hand, is highly personal and difficult to communicate or share with others. Subjective insights, intuitions, and hunches fall into this category of knowledge.

\subsection{Civil servants and civil service}

The USLegal (2007) clearly captures the nature and characteristics of most civil servants and civil service systems all over the world thus:

Civil servants are public employees hired by federal, state, county and municipal governments to provide services to the public. The legislature provides the methods by which civil servants and regulations govern the civil service. On the other hand, a civil service system is established by the legislature, which may delegate to a board of civil service commissioners the authority to make rules consistent with existing laws, to conduct investigations, and generally to exercise any and all administrative measures necessary and proper to achieve the objectives and purposes of the civil service laws. Appointments to positions in the civil service are normally made from eligibility lists composed of persons meeting the established qualifications as determined by tests and civil service examinations. The procedures for the hiring and firing civil servants are generally more regulated and less discretionary than those for employees in the private sector.

The US Legal (2007) further explains that civil service positions are often associated with a bureaucracy, which is characterised by a hierarchical authority structure, task specialisation, and extensive rules. Bureaucracies are often regarded in a negative light due to perceived unresponsiveness to the public's needs. Critics of the civil service system allege that since civil servants must be fired "for cause", they lack the incentive to provide the same level of service that employees who can be fired at will possess. They may therefore function in a bureaucratic matter and resist challenges to perform outside the scope of their defined duties (USLegal, 2007).

\subsection{Bureaucracy}

Sinofsky (2005) defines bureaucracy as management or administration marked by hierarchical authority among numerous offices and by fixed procedures. Bureaucracy is mostly associated with civil service and civil servants. Civil servants in all civil services are known to stick to procedures and rules, and cannot perform outside of their defined duties. Bureaucracy is not confined to national governments only, as shown by Benner, Mergenthaler and Rotmann (2008). Benner, Mergenthaler and Rotmann contend that large international public organisations like the United Nations and its organs make mistakes and keep on repeating the same mistakes rather than learning. Sinofsky (2005) avers that "in the world of technology and the Internet, the one who is out with no rules, no processes, and no hierarchy is the one who is going to win big, while all those sloths with their spreadsheets and dashboards are all bunched up trying to plan their way out of a paper bag".

Knowledge management has mostly been associated with profit-making corporations, which may be a major reason for the organisational culture that predominates in the public sector (Ondari-Okemwa and Smith, 2007). In a paper published by Lodge and Kalitowski (2007) on "innovations in government", they argue that:

- Civil services are bloated, rigid, hierarchical and over-centralised

- Monopoly status ensures that the public sector is unresponsive and inefficient

- Government is driven by the interests of producers, not users

- There is an absence of a performance culture

- Civil servants are unaccountable and over-privileged.

These are not very desirable characteristics for the civil service of any government. However, these characteristics are very prevalent in nearly all civil services in sub-Saharan Africa, including the civil service of South Africa. Many top civil servants in sub-Saharan Africa would argue that these characteristics were inherited from the European colonisers and have served the post-colonial civil servants well. The new public (NPM) views the ideal government as being 'flat, flexible, specialised and decentralised' according to Pollitt and Boukaert (2004). For that matter, the NPM model of management advocates a number of reforms meant to remake the public sector in the image of the private sector. The NPM model has attempted to introduce a 'bottom-line' mentality for civil services to operate like the private sector. 


\subsection{Civil services in a changing world}

It may not be very obvious to the top civil servants in Kenya and the rest of sub-Saharan Africa, but civil services all over the world now exist in a rapidly changing world. The demands placed on the civil services are dictated and determined by the wider environment. As it is, civil services all over the world have to adapt themselves to a number of long term societal trends that are changing the ways in which governments are run in the $21^{\text {st }}$ century. Lodge and Kalitowski (2007) identify some of the societal trends as including:

- Globalisation

- Demographic change - especially an ageing and more diverse population

- Global migration flows

- The information technology revolution

- The greatest marketisation and the blurring of boundaries between the public and private

- A less deferential and trusting citizenry

- Rising public expectations of government

- A more intrusive mass media

- Increasing numbers of the so-called 'wicked problems' that require joined-up, cross-boundary responses

- Problems that can only be addressed through co-production and behavior change.

According to Pinchot and Pinchot (1993), institutions are changing as the relationship between employee and employer alter in deep and permanent ways in response to the need for all to contribute their intelligence, creativity, and responsibility to society. It is now expected that employees - both in the public and private sectors - should be innovative, care for customers, work in teams and collaborate with others, as well as follow their own initiative rather than just follow orders. The situation in the public service is, however, complex and fraught with anomaly - while the members of the public are on the one hand the customers of the public service, they are on the other, as tax payers, the employers of all public agencies.

In an address to the African Management Development Institutes Network Conference, Minister Geraldine FraserMoleketi $^{4}$ (2007) underscores the importance of knowledge management in the African civil service of the $2 I^{\text {st }}$ Century. Fraser-Moleketi asserts thus:

The $21^{\text {st }}$ Century African public service has to be a learning organisation, a learning organisation in which people at all levels, individually and collectively, are continually increasing their capacity to produce results they really care about, where the organisation encourages new ways of thinking, where the collective vision of creating the best is liberated, and where everybody continuously learns how to learn together. If the African civil service is to lead Africa to attain its commitments to the Millennium Development Goals, new ways of doing business and continuously solving problems is essential (Fraser-Moleketi, 2007).

Over the years, society has evolved from an agrarian base through an industrial metastasis, to an information and now emerging knowledge era. Each of these eras has been characterised by specific social attributes and forms of political and cultural organisation. According to O'Hare (2002) the emerging knowledge society presents a set of new imperatives for governments and new challenges and opportunities for society as a whole. The key factor in the information/knowledge society is the generation and exploitation of knowledge; according to the World Bank (2007), today's most technologically advanced economies are truly knowledge-based. The European Commission's (2000) Joint Research Centre estimates that as much as 70 to 80 percent of economic growth is now said to be due to new and better knowledge.

It is claimed that the $2 \mathrm{I}^{\text {st }}$ century has ushered in an information and knowledge revolution that is of the same magnitude as that of the industrial revolution in the $18^{\text {th }}$ and $19^{\text {th }}$ centuries. The pace of change currently being experienced is driven by unprecedented information technology advances, which present considerable challenges for governments the world over. Information and knowledge have become resources governments should manage prudently to enhance the delivery of basic government services to the public.

In a knowledge economy, innovation and the capacity of the system to create and disseminate the latest scientific and technical information are important determinants of prosperity (David and Foray 1995; OECD 1997). While knowledge and its management have generally been credited with improving productivity and establishing more effective management and government service delivery to citizens in the developed world, this has not been the case with Kenya and many other countries in sub-Saharan Africa - which may not be considered to be knowledge economies. The large divide between the economically advanced knowledge-based regions and the developing regions has meant that Kenya, like most other countries in sub-Saharan Africa, has not as yet effectively integrated knowledge management into government agencies. This is not because knowledge is not generated and used in government agencies in Kenya, but

4. Geraldine Fraser-Moleketi is a former South African Minister for the Department of Public Service and Administration 
because knowledge has not yet been leveraged effectively (Ondari-Okemwa, 2006). Governments in the developed countries have, furthermore, optimised information and communication technologies (ICT's) as knowledge management enablers. Kenya lags far behind such developed countries in as far as the application of ICT's are concerned, and this has impacted on the practice of knowledge management and the benefits such practices may have on governance efficacy and service delivery.

This article is thus based on an examination of the role that knowledge management can play to support governance, performance effectiveness, and service delivery in government agencies in Kenya. The article also addresses the challenges and problems which act as impediments to leveraging knowledge to enhance performance and delivery of basic government services and Kenya's role in the knowledge economy.

\section{Research methodology}

The authors adopted one major approach for collecting data for this study. A literature review was conducted on the general topic of knowledge management to have a general understanding of the broad topic. A literature review was then conducted on the civil service, the public sector and knowledge management in the civil service and/or the public sector. Finally, a literature survey was conducted on knowledge management the Kenyan civil service. There was not much published literature on knowledge management in the Kenyan civil service, and the literature survey scope was broadened to cover knowledge management in the civil services of sub-Saharan African countries. This paper was further informed by a study for a thesis conducted by Ondari-Okemwa (2006) on the practices, procedures and challenges of managing knowledge in Kenya's government-owned organizations.

Table I: Kenya at a Glance

\begin{tabular}{ll}
\hline Population, 2006 & $35.1 \quad$ (millions) \\
GDP, 2006 & 23.2 (billions, current US\$) \\
GDP per capita, 2006 & I, 34I (US\$) \\
& \\
Sector value-added, 2004 & (as percentage of GDP) \\
Agriculture & 25 \\
Industry & 16 \\
Services & 53 \\
& \\
Human Development Indicator Rank, 2004 & I52 (out of I77 economies) \\
\hline
\end{tabular}

Source: Economist Intelligence Unit (2007); United Nations Development Programme (2006).

\section{Kenya at a Glance}

Kenya, as a developing country in the sub-Saharan region of Africa, faces all the economic and socio-political challenges typically encountered by such countries. These factors are clearly reflected by the data in Table I above and Table 2 below. In Table I a summary is given of Kenya's 2006 population data, its 2004 gross domestic product (GDP) and human development indicators.

Table 2: Kenya's knowledge economy readiness (World Bank, 2007)

\begin{tabular}{lcc}
\hline \multicolumn{1}{c}{ Index } & $\begin{array}{c}\text { Kenya (most recent) } \\
\text { Group: All }\end{array}$ & $\begin{array}{c}\text { Kenya (2004- 2005) } \\
\text { Group: All }\end{array}$ \\
I. Knowledge Economy Index (Average of 3,4,5,6) & 2.62 & 2.39 \\
2. Knowledge index (Average of $4,5,6)$ & 2.76 & 2.31 \\
3. Economic Incentive and Institutional Regime & 2.21 & 2.63 \\
4. Education & 1.83 & 1.97 \\
5. Innovation & 4.18 & 4.11 \\
6. ICT & 2.28 & 0.85 \\
\hline
\end{tabular}

Table 2 above shows how Kenya scores in the World Bank's assessment of a country's readiness to become a knowledge economy. While the highest possible score is 10, Kenya scored far below average (5) for knowledge economy, knowledge index, economic incentive and institutional regime, education, and information communication technology (ICT). The 
highest score, albeit still below average, was for innovation. The World Bank's assessment of Kenya's preparedness for a knowledge economy implies that Kenya is far from being a knowledge economy.

\section{Knowledge society}

Although the concept of a knowledge society (also sometimes referred to as a knowledge economy) may not currently have a clear-cut or universally accepted definition, certain distinguishing characteristics have generally been identified. These include, but are not limited to, an economy that depends on knowledge for growth, the provision of superior products and services, highly trained and educated people, and knowledge supplanting the traditional resources of production (labour, land and capital) (Drucker 1993). In such a society knowledge workers play a pivotal role and managing self-transformation becomes one of the most critical challenges that organisations face. Organisations therefore have to be prepared to continuously improve, innovate, and develop new applications. Nonaka and Takeuchi (I995) contend that we are now fully embedded in the "knowledge society" as outlined by Drucker.

Evers and Menkhoff (2004) are of the view that the number of consultants and experts is growing world-wide and the quality of their professionalism provides a benchmark for the stage that a knowledge economy or knowledge society has reached. Such experts and consultants, among other things, enable and legitimise political action (politicians and bureaucrats can and do off-load their responsibilities to experts and consultants).

\section{Knowledge management and government service delivery}

Through the public service, every government strives to deliver basic services as effectively as possible. The delivery of basic services may relate to improving the economic infrastructure, improving efficiency and effectiveness, and establishing a business-friendly environment by reducing the cost of setting up and doing business. Government-owned corporations often serve as levers that open growth potential and create macro-economic stability. Riley (2003), however, contends that in the recent years there has been much talk of public cynicism towards politicians and public officials.

According to Riley (2003), much of this cynicism is based, amongst others, on a lack of knowledge and understanding of the inner working of government, a lack of communication that keeps people informed, and governments' failure to engage the ordinary citizens in public policy development. In Kenya, and in other countries in the sub-Saharan region, members of the public are rarely involved or consulted in matters of public policy formulation or implementation. This we suggest is directly related to a culture of secrecy that is still prevalent in government services in many countries in Africa. This is exemplified by the Swahili word for government, which is serekali and which when translated means "top secret" (Ondari-Okemwa, 2004). Riley (2003) has therefore suggested that knowledge management programmes may contribute to creating renewed faith in government bodies through the creation of an interactive government engaged in wide dialogue with an interactive citizenry.

Wiig (2002) is also of the opinion that knowledge management could make a significant contribution to rendering a country's public administration more effective. He specifically identifies the following areas where KM can play a role:

- Enhancing decision-making within the public service

- Aiding members of the public to participate effectively in public decision-making

- Building competitive societal intellectual capabilities and

- Developing a knowledge competitive workforce.

He further argues that the knowledge management objectives for the public administration in a democracy may be expressed as the intent to provide

- Effective public administration services and functions to implement the public agenda

- A stable, just, orderly and secure society

- Acceptable quality of life, particularly through building, maintaining, and leveraging commercial and public intellectual capital

- A prosperous society for developing its citizens to become competent knowledge workers and its institutions to be competitive.

Heck and Rogger (2004), in turn, suggest that knowledge management interventions in the public service could in the mid - and long term achieve the following:

- Significant improvement of service delivery in terms of efficiency, transparency and quality as a result of the transparent and configurable flow of information and more equitable distribution of responsibilities;

- Creating a public administration that is based on well organised and technically functional internal business processes, e.g. the development of e-government projects; and

- Leveraging and optimizing skills that are related to workflow in the various government departments.

Wexler (200I) specifically refers to the benefits of utilising the visual technique of knowledge mapping to coordinate, simplify, highlight and navigate through complex webs of knowledge possessed by institutions. He emphasises the role

SA Jnl Libs \& Info Sci 2009, 75(I) 
that knowledge mapping can play to render internal experts' knowledge explicit in a visual presentation that can be easily understood and shared. Knowledge maps, if created in the civil service, can provide an overview of expertise that resides in government departments and the identification of the people who possess such expertise.

It is clear that there are numerous applications and benefits that can derive from implementing effective knowledge management strategies in the public sector. It is therefore not surprising that knowledge management is increasingly playing a more important role in this environment. The authors, however, suggest that while this might be true in more developed countries, it does not necessarily pertain to many countries in Africa. The study conducted by OndariOkemwa (2006) clearly indicates that Kenya has not as yet effectively integrated knowledge management into its government agencies, and that as a consequence the delivery of basic government services is generally not at required levels in terms of quality, efficiency and transparency.

\section{Integrating knowledge management in the civil service of Kenya}

The benefits that knowledge management can bring to any civil service can only be realised if KM practices are effectively integrated into public service operations. This can be a very complex process and will depend on a government's approach to the situation. For example, it is crucial that any knowledge management programme should take into account both tacit and explicit knowledge, as well as the dominant managerial model of governance. A further factor is the extent to which individuals are both willing to and able to maximise their own value and this, in turn, may dictate how knowledge is structured and presented to best enhance the decision-making capabilities of civil servants.

Another aspect to consider is that the introduction of knowledge management practices into a civil service will not necessarily mean that the relevant civil servants will be willing to share knowledge. Within any bureaucratic structure, such as predominates in the public sector, there is an unspoken motivation not to share knowledge, since according to Weber (1978) the power of any bureaucracy rests upon two types of knowledge: "technical know-how" and "official information". Considering that technical know-how may be shared by many, a civil servant's competitive advantage may lie in official information. Knowledge sharing thus decreases as the level of competition within an organisation increases. The investigation by Ondari-Okemwa (2006) indicates that these scenarios are particularly prevalent in Kenya and that it is not uncommon for civil servants in that country to hoard information and call it "classified information" or an "official government secret". An effective knowledge management would encourage sharing of knowledge and information.

In introducing and integrating knowledge management in the civil service of Kenya, it should be noted that an overly techno-centric approach may fail to produce a culture and context which nurtures organisational learning. Damodaran and Olphert (2000) are of the view that the overemphasis of technological issues is the most common cause of the failure of knowledge management in organisations. They instead recommend a more socio-technical approach, which has as its objective the management and sharing of knowledge to support the achievement of organisational goals. Fitzgerald (2008) contends that social networking tools promise to help companies harness inside the heads of their employees and put it to work for the business. Fitzgerald (2008) argues thus:

Those dealing with knowledge management (KM) have always faced the challenge of getting information out of people's heads and into a database. Social computing tools seem like a good way to help, since they encourage people to share their knowledge with others, and that expertise can be easily captured.

\section{Impediments to producing, processing and sharing knowledge in the Kenyan civil service}

A major function of any knowledge management programme is to ensure that knowledge, whether tacit or explicit, is successfully shared and utilised within the organisation (Sun, 2004). The authors have, however, observed that in the Kenyan civil service a number of impediments impact on the effective generation, processing and sharing of knowledge required to enhance performance and service delivery.

\section{I Citizens as effective policy partners}

Ondari-Okemwa's (2006) study clearly indicates that the Kenyan civil service is not geared towards involving its citizens in policy development and in preparing them to become effective policy partners. Policies are formulated and implemented by government policy makers without any input from the citizenry; as a consequence ordinary citizens are unaware of the effect that the policies that have been promulgated have on their lives. Some organisations in European countries have devised ways of involving citizens in formulating and implementing public policies which affect the citizenry. For example, in the run-up to the 2009 Euro-elections, the European Citizens' Consultations 2009 (ECC 2009) will bring together randomly selected citizens from all 27 EU Member States to discuss key challenges facing the EU with each other, and then with policy-makers. ECC 2009 will focus on the issues currently of greatest concern to EU citizens, seeking to answer the question: "What can the EU do to shape our economic and social future in a globalised world?" 
'Family and social welfare' were among the topics chosen by citizens for in-depth discussion at ECC 2007, and the latest Eurobarometer opinion poll shows that social and economic issues remain high on the public's agenda. As the EU institutions begin work on a post-2010 successor to the Lisbon Agenda for economic growth and competitiveness, ECC 2009 will also provide timely and relevant input for decision-makers.ECC (2009) has six objectives:

- promoting interaction between citizens and policy-makers: fostering debate between citizens and policymakers in the run-up to - and after - the European elections;

- citizens as policy advisors: feeding citizens' opinions into the political debate at both European and national levels;

- citizen participation as a policy instrument of the future: mainstreaming trend-setting and long-term oriented citizen consultations at the European level;

- closing the gap between the EU and its citizens: bringing the EU closer to citizens and citizens closer to the EU;

- increasing the general public's interest in the EU: generating substantial media coverage of the dialogue between the EU and its citizens;

- partnerships in participation: deepening European co-operation within existing civil society networks and their respective partner networks, as well as e-participation provider.

This kind of citizen participation in making policies lacks in Kenya as shown by Njonjo (2009) who in an opinion newspaper article implores the government of Kenya to involve the Kenyan public in law-making. Members of the public in Kenya and in the larger sub-Saharan Africa are hardly involved in policy or law-making. It is clear that such a situation is untenable and it is suggested that by introducing effective knowledge management programmes the Kenya government could alleviate the problem and enable its citizenry to become effective policy partners.

\subsection{E-governance and a customer-centred public administration}

According to Oakley (2003), e-governance is about the use of information technology to raise the quality of the services governments deliver to citizens and businesses. It is hoped that it will also reinforce the connection between public officials and communities, thereby leading to a stronger, more accountable and inclusive democracy. Customer-centred public administration puts emphasis on customer involvement and quality of public service (Ra and Joo, 2005). 'Value for money' and/or 'putting the customer first' are some of the issues addressed by customer-centred public administration. According to Skelcher (1992), 'customer' refers to the direct users of public services, the direct or indirect recipients of public organisations' activity, those gaining benefit or disbenefit from public organisations' activity or inactivity, and those who do not fall into any of the above groups but have an interest in public services. Skelcher further argues that adopting the customer as the focus for improvements in public service quality requires public organisations to adopt some particular: (I) public services should be delivered to meet the customer's needs rather than the organisation's predisposition; (2) public authorities should seek to maximise people's involvement in shaping the choices available to them. The customer-oriented approach, together with an increase in customer power, is expected to bring about improvements in public services.

Heck and Rogger (2004) suggest that the introduction of e-governance enables public administrations to move towards more customer-centred services as it brings with it a redistribution of tasks and hence of knowledge. It was observed that the Kenyan civil service is not particularly customer-centred and that service delivery is of uneven quality and availability. Citizens receive services as and when the civil servants have the time and ability to render them, service delivery is often delayed and of a poor quality. It is suggested that if the Kenyan government were to introduce egovernance there would be better redistribution of tasks and knowledge and hence a move towards customer-centred services and enhanced service delivery. Knowledge management would be one of the pillars enhancing service delivery in the Kenyan civil service.

\subsection{A bureaucratic public administration}

The Kenyan public administration is still entrenched in traditional bureaucratic procedures where staff are not given due recognition for their professionalism and knowledge, and where innovation, knowledge generation and leadership are not rewarded. As a consequence, staff are appointed to senior positions based on whether they are efficient managers rather than whether they are knowledge leaders. The environment in the public service of Kenya does not therefore encourage employees to acquire, share and manage knowledge at individual and departmental levels, nor to network and collaborate, or to document tacit knowledge (e.g. such as lessons learned).

\subsection{Cultural factors}

Culture can act as both an enabler and an impediment to the generation, distribution and sharing of knowledge and information. According to Barnard, Cloete and Patel (2003), in a developing context, cultural factors are particularly important for the successful deployment of most electronic services. They refer specifically to the tension that often exists between many traditional cultures and the modern electronic environment. Kenya is a developing nation and has 
not as yet fully adapted to the electronic environment. Careful consideration should therefore be given to cultural factors when such technologies are deployed. A culture of sharing knowledge and information is still lacking in Kenya. The traditional cultures in Kenya and the rest of sub-Saharan Africa discourage sharing of knowledge and information.

\subsection{Literacy levels in Kenya}

Although the World Bank (2007) has recorded an impressive adult literacy rate of $77.1 \%$ for persons aged I5 and above in Kenya, these figures merely represent functional literacy rates. In many regions, especially in the rural areas, low literacy rates prevail and information literacy rates, even among civil servants, are low and this can be a hindrance to distributing and sharing knowledge and information.

Table 3: Variables indicating Kenya's level of preparedness for a knowledge society (World Bank 2007)

\begin{tabular}{|c|c|c|c|c|}
\hline \multirow[t]{3}{*}{ Variable } & \multirow{2}{*}{\multicolumn{2}{|c|}{$\begin{array}{c}\text { Kenya (most recent) } \\
\text { Group: All }\end{array}$}} & \multirow{2}{*}{\multicolumn{2}{|c|}{$\begin{array}{c}\text { Kenya (1 995) } \\
\text { Group: All }\end{array}$}} \\
\hline & & & & \\
\hline & actual & Normalised & actual & Normalised \\
\hline Annual GDP growth (\%) & 2.94 & 2.69 & 2.40 & 3.05 \\
\hline Human development index & 0.491 & 1.23 & 0.523 & 2.00 \\
\hline Tariff \& Nontariff Barrierse & 4.00 & I.7। & 4.00 & 4.03 \\
\hline Regulatory Quality & -0.32 & 3.64 & -0.43 & 2.27 \\
\hline Rule of Law & -0.94 & 1.29 & -0.83 & 1.59 \\
\hline Researchers in R\&D / Mil. People & $\mathrm{n} / \mathrm{a}$ & $\mathrm{n} / \mathrm{a}$ & $\mathrm{n} / \mathrm{a}$ & $\mathrm{n} / \mathrm{a}$ \\
\hline Scientific and Technical Journal Areticles / Mil. People & 7.89 & 3.74 & $1 \mathrm{I} .40$ & 4.27 \\
\hline Patents Granted by USPTO /Mil. People & 0.25 & 4.62 & 0.04 & 3.94 \\
\hline Adult Literacy Rate ( $\%$ age 15 and above) & 73.60 & 2.42 & 77.10 & 3.23 \\
\hline Gross Secondary Enrolment & 48.00 & 2.09 & 24.40 & 1.40 \\
\hline Gross Tertiary Enrolment & 2.90 & 0.96 & 2.70 & 1.28 \\
\hline Total Telephones per I 000 People & 85.00 & 1.82 & 9.50 & 1.82 \\
\hline Computers per I,000 People & 13.20 & 1.90 & 0.70 & 0.73 \\
\hline Internet Users per I,000 People & 44.80 & 3.11 & 0.00 & 0.00 \\
\hline
\end{tabular}

DP growth and Patent Applications Granted by the USPTO are the annual averages for 200I-2005 (most recent) and I993-1997 (1995). Most of the remaining recent data is for 2004-05.

\section{Kenya's level of preparedness to become a knowledge society}

According to the World Bank (2007), for a country or a region to harness its human and social capital so that it can take its place among today's knowledge economies, it takes less financial investment than policy reform. They therefore suggest that a country should embark on policy initiatives that would transform its education system to meet the demands of a global economy driven by advances in knowledge and technology; encourage private businesses to invest in research and development; and create business and research initiatives that foster innovation.

Research by the World Bank Institute (World Bank 2007) has found that a policy framework that can promote knowledge economies rests on at least four pillars, all involving long-term commitment. The first pillar relates to the provision of economic incentives and an institutional environment that encourages entrepreneurship, the development of new activities and modernisation. The second pillar that a country needs to build is a skilled and flexible labour force. A country should provide quality education and life-long learning to its people, both male and female. The third pillar relates to building a knowledge society where dynamic information and telecommunications infrastructure provide efficient services and tools to all sectors of society. As a country sets out to restructure and develop its telecommunications infrastructure, it should ensure wider and less costly access to telephone lines and to the Internet. The fourth pillar refers to the creation of a system of science and research centres, universities, and other organisations that can interact to promote innovation and create new products and services. Building such innovation systems would facilitate the pooling of resources for research projects, ensuring financing and/or commercialisation of research, promoting excellence through professional associations of experts and peer-review mechanisms, and the creation of specialised research and development centres.

In their assessment of how Kenya fares with reference to these pillars, the World Bank (2007) scores Kenya below average on all four of the main pillars outlined above. Table 3 further shows how Kenya scores in the World Bank's assessment of a country's readiness for a knowledge economy. The highest possible score is 10 . Once again it is seen that 
Kenya scores below average for all categories and that the country is particularly weak in the field of tertiary education. These factors would indicate that Kenya has not yet become a knowledge society, and a considerable amount of work needs to be done before it can become one.

Closely related to these factors is a country's level of readiness to introduce e-governance. It is generally accepted that information and communication technologies (ICTs) are important enablers that ensure that knowledge management programmes run effectively. It is further clear that the utilisation of ICTs or e-governance in the public sector has become a crucial factor to ensure good service delivery. According to Coleman (2005), there has been a rapid growth of information and communication technologies which can transform the generation and delivery of public services, thereby reconfiguring relationships between government and citizens (G2C0), governments and businesses (G2B) as well as within and between governments (G2G). Coleman further contends that e-governance has the potential to:

- improve the performance of public institutions and make them more transparent and responsive;

- facilitate strategic connections in government by creating joined-up administrations in which users can access information and services via portals or "one-stop-shops"; and

- empower civil society organisations and citizens by making knowledge and other resources more directly accessible.

The study conducted by Ondari-Okemwa (2006) as well as the assessments made by the World Bank (2007) (as outlined above) clearly indicate that Kenya lacks an adequate ICT infrastructure to enable it to effectively implement egovernance and knowledge management programmes in the public sector. We therefore advocate that the ICT infrastructure needs to be significantly upgraded to ensure that it is at the appropriate level of sophistication to implement effective e-governance and knowledge management programmes. We suggest that if this is can be achieved the quality and promptness of service delivery in the public sector will improve significantly.

\section{Conclusion}

From the discussion above it is clear that knowledge management has the potential to improve service delivery in the civil service. It is however further evident that knowledge management has not as yet been adequately integrated into the Kenyan civil service and that the benefits thereof cannot be realised until such time as sufficient integration has taken place. The Kenyan civil service, which is particularly embedded in bureaucracy, provides very few incentives that encourage civil servants to generate, distribute and share knowledge and information. Many employees in the Kenyan civil service are traditional career civil servants who cannot envisage and appreciate the potential of knowledge management and the benefits of knowledge leveraging. Many of these civil servants are still wary of sharing knowledge or information as they have the perception that by hoarding knowledge they enhance their value and competitiveness. The general work environment in the civil service in Kenya thus does not engender or encourage the generation, distribution and sharing of knowledge.

Kenya consequently has a long way to go before it becomes a knowledge society where knowledge is freely generated and effectively used in the public sector. These factors are clearly indicated by the low scores the country achieves on the variables which determine a country's capacity to effect a knowledge economy. The civil service is further plagued by numerous impediments that inhibit the generating and sharing of knowledge, the most severe of which are its entrenched bureaucracy, lack of incentives, cultural barriers and technology inadequacies. With reference to technology barriers it is evident that the ICT infrastructure urgently needs upgrading to facilitate the introduction of e-governance which in turn will enable the effective implementation of knowledge management programmes. We firmly believe that if the delivery of basic government services is to be improved, the civil service should be encouraged to adopt knowledge management practices that are firmly integrated into service delivery procedures. Civil servants should further be encouraged and motivated to actively generate, manage and share knowledge and information.

\section{References}

Alavi, M. and Leidner, D.E. 1999. Knowledge management systems: issues, challenges and benefits. Communications of the AIS, (I) Article 7. [Online]: http://cais.isworld.org./articles/I-7/article.htm. Accessed I6 May 2007.

Barnard, E., Cloete, L. and Patel, H. 2003. Language and technology literacy barriers to accessing government services In: Traunmüller, R. (Ed.), Electronic government. [Online]: http://www.meraka.org.za/pubs/barnardeO3languagebarriers.pdf. Accessed 06 March 2007.

Benner, T., Mergenthaler, S. and Rotmann, P. 2008. Organizational learning in the UN Peace Operations Bureaucracy: Conceptual foundations and empirical perspectives. A paper prepared for the 49th annual International Studies Association Convention, San Francisco, 28 March. [Online]: http://www.gppi.net/fileadmin/gppi/ Benner_Rotmann_Mergenthaler_OL_ Peace_Operations_ISA_2008_Paper_Draft_Final.pdf. Accessed 22 April 2008.

Coleman, S.2005. African e-governance - opportunities and challenges. [Online]: http://www.commissionforafrica.org/english/report/ background/coleman_background.pdf. Accessed 28 August 2007.

Damodaran, L. and Olphert. W. 2000. Barriers and facilitators to the use of knowledge management systems. Behaviour and Information Technology, 19(6):405-4I3.

SA JnI Libs \& Info Sci 2009, 75(I) 
David, P. and Foray, D. 1995. Assessing and expanding the Science and Technology knowledge base. STI Review, No. I6, OECD, Paris.

Drucker, P. 1993. Post-capitalist society, Butterworth Heinemann, Oxford.

Economist Intelligence Unit. 2007. Kenya: Country overview. [Online]: http://store.eiu.com/country/KE.html?ref=country_list. Accessed 28 August 2007.

European Citizens Consultation. 2009. European Citizens' Consultation on the future of Europe: building on the successful dialogue of 2007. [Online]. www.european-citizens-consultations.eu/files/ECC\%2009\%20Project\%20Description\%20final.pdf. Accessed I I May 2009.

European Commission, Joint Research Centre. 2000. Futures Project Synthesis Report. [Online]: http://www.jrc.es. Accessed I8 February 2007.

Evers, H.-D. and Menkhoff, T. 2004. Expert knowledge and the role of consultants in an emerging knowledge-based economy. Human Systems Management, 23(2): I23-135.

Fitzgerald, M. 2008. Why Social Computing Aids Knowledge Management. [Online]: http://www.cio.com/article/395//3/ Why Social_Computing_Aids_Knowledge_Management. Accessed 08 May 2009.

Fraser-Moleketi, G. 2007. SA: Fraser-Moleketi: African Management Development Institutes conference. Opening address by Geraldine Fraser Moleketi at the African Management Development Institutes Conference, Midrand, South Africa. [Online]: http://www.polity.org.za/article.php?a_id=I / 6056. Accessed 04 August 2007.

Heck, U. and Rogger, A. 2004. Knowledge management for e-service-delivery - a conceptual approach within e-government. In: Wimmer, M.A. (Ed.) Knowledge management in Electronic government.[Online]:http://www.springerlink.com/content/ rr3bueqacmkd3yxu/fulltext.pdf. Accessed 27 September 2007.

Lodge, G and Kalitowski, S. 2007. Innovation in government: international perspectives on civil service reform. [Online]: $h t t p: / /$ www.uquebec.ca/observgo/fichiers/88022_GRA2.pdf. Accessed 22 September 2008.

Njonjo, M. 2009. Involve the public in law-making, Daily Nation, Monday, II May 2009. [Online] Available: http:// www.nation.co.ke/oped/Opinion/-/440808/595858/-/476wj2/-/index.html. Accessed I I May 2009.

Nonaka, I. 1994. A dynamic theory of organisational knowledge creation, Organization Science, 5(I): I4-37.

Nonaka, I. and Konno, N. 1998. The concept of "Ba": building a foundation for knowledge creation. California Management Review, 40(3):40-54.

Nonaka, I. and Takeuchi, H. 1995. The knowledge creating company: how Japanese companies create the dynamics of innovatio. Oxford University Press, New York.

Oakley, K. 2003. What is e-governance? [Online]: http://www.coe.int/t/e/integrated_projects/democracy/02_Activities/0I_e-governance/. Accessed I I May 2009.

OECD. 1997. National Innovation Systems, OECD, Paris. [Online]: http://www.oecd.org/dataoecd/35/56/2 I0I733.pdf. Accessed 28 February 2008.

O'Hare, D. 2002. Building the knowledge society. In: Information Society Commission, Report to Irish Government. [Online]: http:/ /www.isc.ie/downloads/know.pdf. Accessed 25 May 2007.

Ondari-Okemwa, E. 2004. Impediments to promoting access to global knowledge in sub-Saharan Africa, Library Management, 25(8/9):36I-375.

Ondari-Okemwa, E. 2006. An investigation into the practices, procedures, and challenges of knowledge management in governmentowned organizations in Kenya. Unpublished PhD. thesis, University of Cape Town, South Africa.

Ondari-Okemwa, E. and Smith, G. 2007. Knowledge management and enhanced government-service delivery in Kenya. In Proceedings of the $4^{\text {th }}$ International Conference on Intellectual Capital, Knowledge Management and Organizational Learning, University of Stellenbosch Business School, South Africa, I5-16 October. Ed. Dan Remenyi, 285-292.

Pinchot, G. and Pinchot, E. 1993. The end of bureaucracy and the rise of the intelligent organisation, Berret-Koehler, San Francisco.

Pollitt, C. and Bouckaert G. 2004. Public management reform: a comparative analysis. 2nd edition, Oxford University Press. [Online]: http://www.kmafrica.info/downloads/nisha.pdf. Accessed I 2 May 2007.

$\mathrm{Ra}, \mathrm{H}-\mathrm{M}$ and Joo, J. 2005. Evaluating customer-care reforms in Korean local governments: possibilities and limitations of reform measures for civil application. [Online]: http://ras.sagepub.com/cgi/content/abstract/7//3/425. Accessed I4 May 2009.

Riley, T.B. 2003. Knowledge management and technology: international tracking survey report, Government telecommunications and informatic services, Public Works and Government Services, Canada. [Online]: www.electronicgov.net/pubs/research_papers/ tracking03/Int/TrackingRptJune03no2.pdf. Accessed 17 March 2007.

Sinofsky, S. 2005. Steven Sinofsky's Microsoft Tech Talk. Bureaucracy, threat or menace? Either, both or neither? Or it depends! [Online]: http://blogs.msdn.com/techtalk/archive/2005//0/05/477633.aspx. Accessed 08 June 2007.

Sun, Z. 2004. A waterfall model for knowledge management and experience management, In: Proceedings of the Fourth International Conference on Hybrid Intelligent Systems (HIS'04). [Online]: http://csdl.computer.org/dl/proceedings/his/2004/ 2291/00/22910472.pdf. Accessed 18 April 2007.

United Nations Development Programme. 2006. Kenya National Human Development Report. [Online]: http://www.ke.undp.org/ 06NHDRreport.pdf. Accessed 22 February 2007

Weber, M. 1978. Economy and society, 2 Vols. edited by G. Roth and C. Wittich, Berkeley: University Press, California.

Wexler, M. 200I. The who, what, why of knowledge mapping”, Journal of Knowledge Management, 5(3):249-263.

Withers, G. 2006. The bureaucracy and the academy [Managing Knowledge: Glenn Withers]. In The Canberra Times, 04 July. [Online]: http://www.crawford.anu.edu.au/events/announcements/news.php?year=2006. Accessed 06 June 2006.

Wiig, K.M. 2002. Knowledge management in public administration. Journal of Knowledge Management, 6(3):224-239.

USLegal. 2007 Legal definitions: Civil service law and legal definition.[Online]: $h t t p: / / d e f i n i t i o n s . u s / e g a l . c o m / c / c i v i l-s e r v i c e /$. Accessed 24 May 2007.

World Bank. 200I. Working on administrative and civil service reform. [Online]: http://wwwl.worldbank.org/prem/acr/ad.html. Accessed 21 March 2007. 
World Bank. 2007. World Development Indicators. [Online]: http://info.worldbank.org/etools/kam2/KAM_page2.asp. Accessed 29 June 2007.

World Economic Forum. 2007. The Africa Competitiveness Report. [Online]: http://www.weforum.org/pdf/gcr/africa/investment/ kenya.pdf. Accessed 27 June 2007. 